\title{
La evaluación educativa en México, ¿un proceso?
}

Xochithl Guadalupe Rangel Romero

Y el niño contestó a su padre: Y en definitiva, ¿en qué estoy mal?

Diplomado para maestros en servicio RIEB, 2009

L

as instituciones educativas tienen como fin principal el seguimiento del proceso de enseñanza-aprendizaje que se traspola a los alumnos. Es preciso hacer notar que todo proceso de evaluación que realizan las instituciones formadoras va encaminado a instruir al educando y a fortalecer el perfil de egreso que éstas ofrecen, en primera instancia; aunque es menester señalar que en un segundo punto, las instituciones formadoras se consolidan como escuelas generadoras de calidad educativa, por lo cual, la evaluación al presente constituye un proceso dentro del modelo de estratificación educativa que tiene que consolidarse en México, dando como corolario que el binomio evaluar y ser evaluado deba ser parte común del lenguaje educativo que impera dentro del Sistema Educativo Mexicano (SEM).

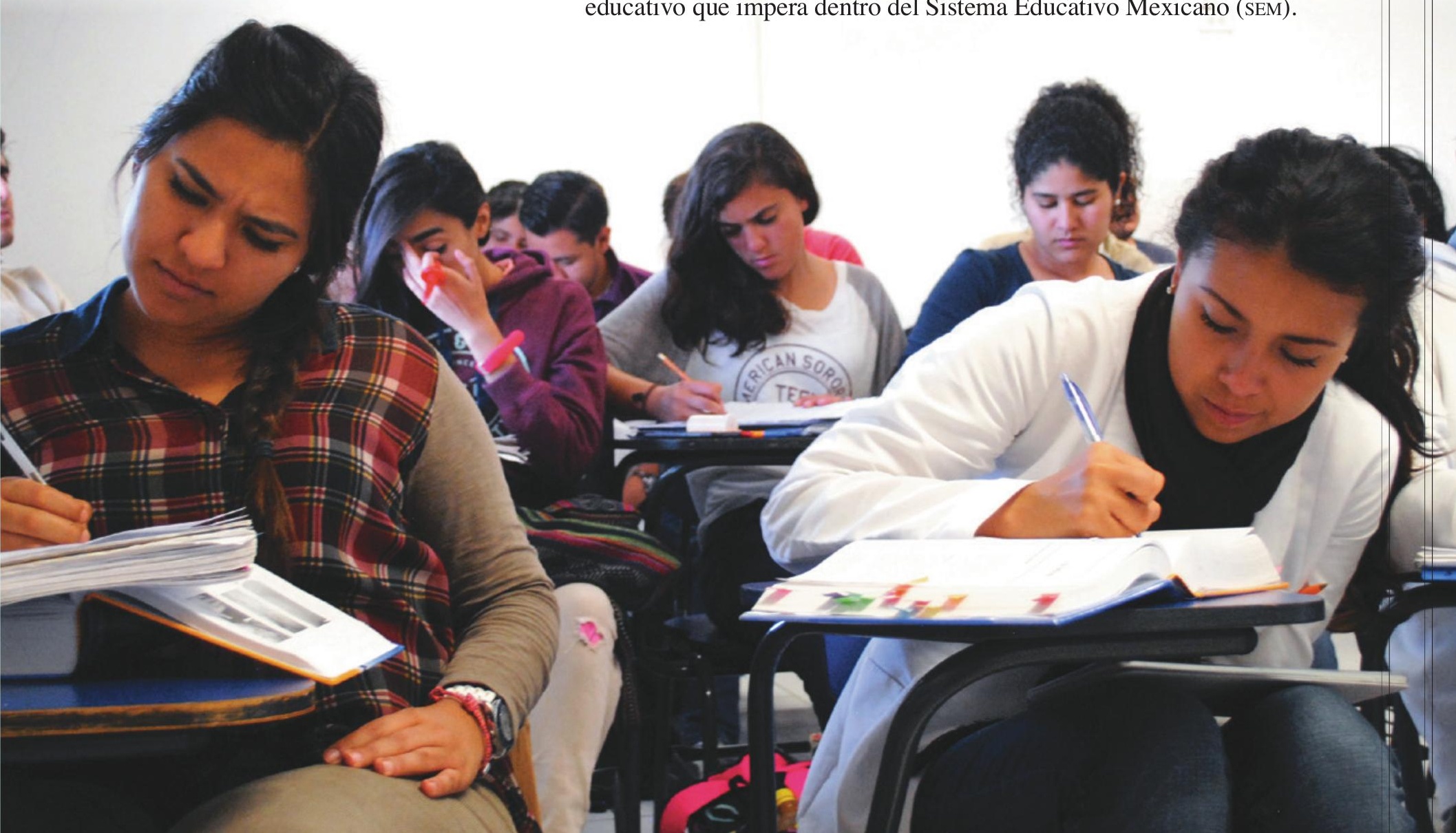


Al presente, uno de los temas en boga en el estado mexicano es el tópico de la evaluación educativa, no sólo por las diversas reformas que ha sufrido el artículo tercero de la constitución federal que así lo refieren, o por la creación del "reciente" Instituto Nacional para la Evaluación de la Educación (INEE), sino porque hoy se (re)conoce la "importancia y las repercusiones del hecho de evaluar o ser evaluado" (FICH, s.a: 1). Lo anterior se justifica en razón de que con una evaluación educativa adecuada se pueden tomar decisiones y gestionar políticas educativas, es por esto que el tema de la evaluación no debe ser una cuestión baladí ni mucho menos teórica, sino que lleva en sí misma una gran importancia: que a partir de la evaluación que se obtenga se tome una decisión sobre hacia dónde y qué hacer.

Por lo anterior, la evaluación, como lo han señalado García y Pérez (1989), es una actividad o proceso sistemático de identificación, recogida, o tratamiento de datos sobre elementos o hechos educativos, con el objetivo de valorarlos primero y, sobre dicha valoración, tomar decisiones. Por esta razón, se considera que la evaluación debe ser un proceso continuo que debe realizar no sólo el Estado como tal, sino la misma institución formadora.

Ahora bien, es preciso hacer notar también que el tópico de la evaluación es una actividad tan importante dentro del SEM que ha caído en un mal entendido, el cual se expresa en el siguiente planteamiento: Hoy el tópico de la evaluación educativa no se limita al rendimiento escolar, meramente, aunque lo anterior se ha convertido en un parteaguas de las funciones que el mismo INEE desarrolla, sino que es preciso reconocer que la evaluación educativa traspola más allá que sólo el rendimiento escolar, por lo cual la evaluación afecta también al currículo, a los docentes, al centro escolar en sí mismo, al sistema, entre otros; para entender el tema de la evaluación educativa, se tiene que dejar atrás que sólo se evalúa al alumno, lo anterior sería tanto como decir que las reformas educativas en México sólo afectan a las instituciones educativas.

Por esta razón, el tópico de la evaluación educativa se ha convertido en un gran avance del reconocimiento del proceso de enseñanza-aprendizaje en México. Es preciso mencionar que los esfuerzos en materia de evaluación en el estado mexicano se han tratado de consolidar a través de los resultados académicos que son obtenidos en diversas pruebas, como lo sería PISA, aunque estos resultados no han sido del todo favorables a México, como lo ha puntualizado la misma Organización para la Cooperación y el Desarrollo Económicos (OCDE), "los resultados del logro académico están considerablemente por debajo de la media de la oCDE" (Santiago Paulo et al., 2012: 34). Lo anterior indica que la evaluación en México se

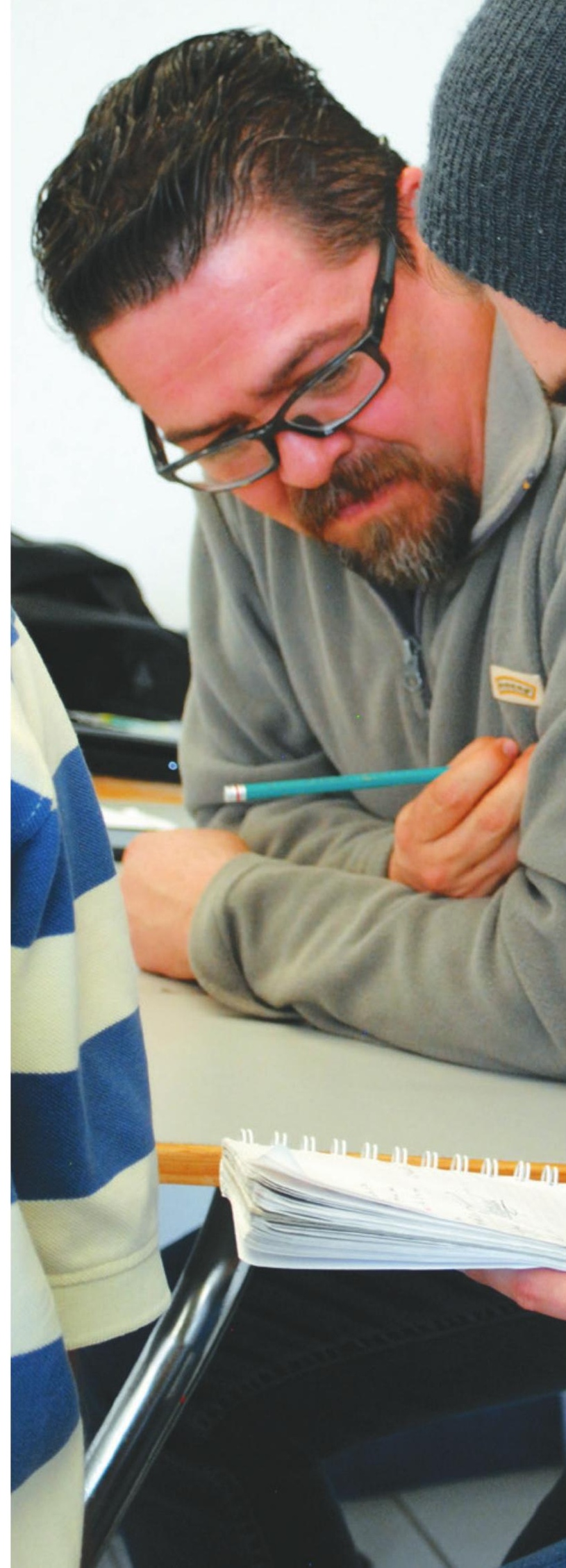




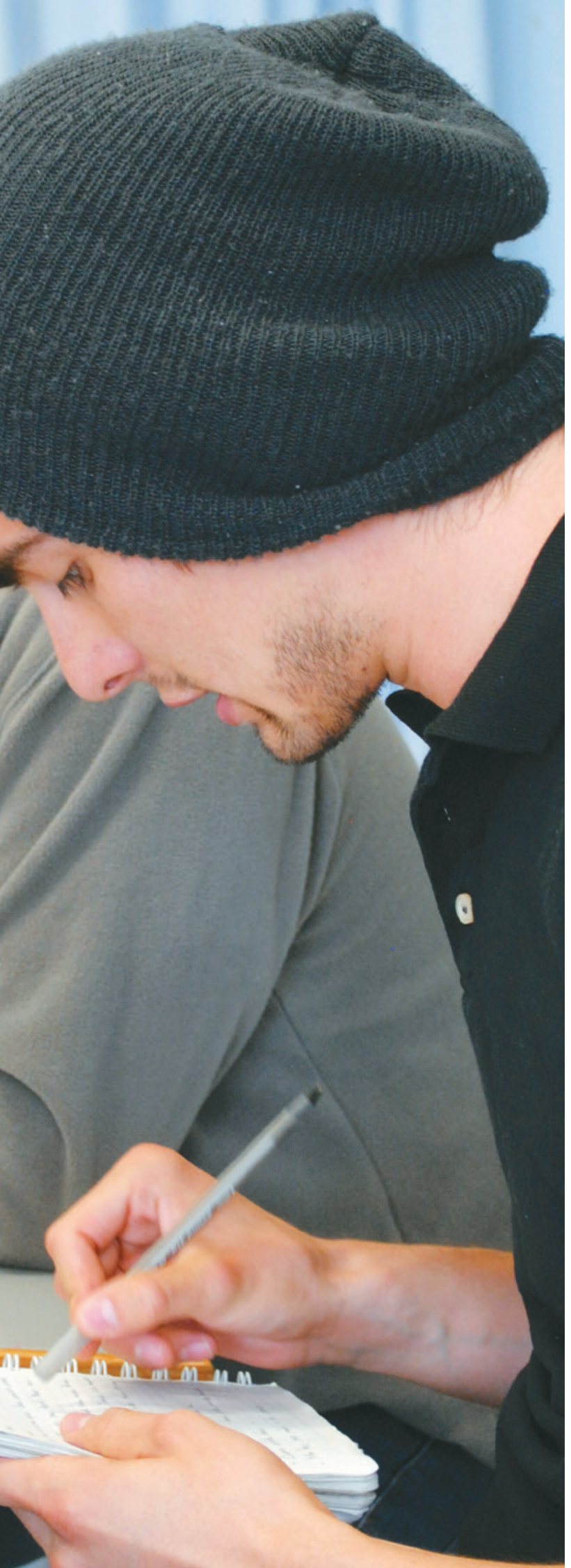

encuentra avanzado, con la finalidad de consolidar las políticas educativas mexicanas.

Es preciso mencionar, entonces, que al presente la evaluación debe ser vista como un proceso continuo, dinámico, flexible y abierto, y que en él confluyen un sinfín de situaciones para poder evaluar o determinar los alcances que se han obtenido en un determinado contexto.

Para el caso mexicano, la misma oCDE (en Santiago Paulo et al., 2012: 41-42) ha señalado que el marco de evaluación en México tiene que estar integrado por cuatro aspectos fundamentales, que son:

- La evaluación de los alumnos.

- La evaluación de los docentes.

- La evaluación de las escuelas.

- La evaluación del sistema.

Es preciso mencionar que la evaluación educativa que se espera en México es el conglomerado de lo que refiere la misma OCDE; no se puede visualizar en México una evaluación sin que se vea expresada en estos cuatro rubros que se mencionan, se cree pertinente establecer que también tiene que ser evaluada la comunidad como aquella que recibe el impacto educativo, propiamente dicha; ahora bien, es pertinente puntualizar que la escuela, como la institución donde se aglomeran los saberes, las actitudes y valores de una sociedad, tiene dentro de sus acciones principales evaluar, es decir, valorar que los alumnos están desarrollando las habilidades y competencias que se pretenden y que éstos se alcancen según el nivel educativo al cual acceden; y además que la misma institución esté generando un cambio dentro de la comunidad; por lo tanto, recordando uno de los fundamentos de la flexibilidad como lo es la diversidad, deben existir varias formas de valorar los aprendizajes de los alumnos y por eso la evaluación debe ser integral, razón por la cual se considera que la evaluación en México debe ser considerada como un proceso, el cual debe estar integrado por una serie de etapas de evaluación, como lo serían el mismo sistema, la institución formadora, la comunidad, los alumnos, y los docentes.

En el marco de la flexibilidad del cual se habla, se trata de evaluar el servicio del cual aprende el alumno; la evaluación debe dar la pauta para reorganizar los procesos de enseñanza y aprendizaje y ser el recurso base para establecer nuevas formas de afrontar las acciones y situaciones que se presenten (San Martí, 2007). 
